\title{
Analysis of Factors Affecting Rice Consumption in Cross River State, Nigeria
}

\author{
*Agbogo, Elias A, *Udouso, Aniedi B and *Tiku, Ejor N \\ *Department of Agricultural Economics/ Extension Cross River University of Technology, Nigeria
}

\begin{abstract}
This study was conducted to evaluate the factors affecting rice consumption in Cross River State of Nigeria. Two hundred and forty (240) rice consumers were randomly selected from twelve (12) purposively selected Local Government Areas in Cross River State. Data were collected using questionnaire. It was discovered that the socio-economic variables that affect rice consumers in the study area were age, marital status, household size, religion and educational level. It was also found that the average monthly income of a respondent, average amount spent on rice per day by one household and the average quantity of rice consumed per meal per household were $\$ 32,154.00, \$ 1,378.00$ and $2 \mathrm{~kg}$ respectively. The results showed that the coefficients of the four explanatory variables selected for the study met the a priori theoretical expectations. The variables included rice consumers disposable income $\left(X_{I t}\right)$, occupational status of the consumers $\left(D_{I t}\right)$, joint effect of income and occupational status $\left(D_{1 t} X_{I t}\right)$, brand of rice $\left(D_{2 t}\right)$, price of rice $\left(X_{2 t}\right)$ and the joint effect of rice brand and own price $\left(D_{2 t} X_{2 t}\right)$. The results showed that disposable income variable had a magnitude of 0.352 and was positive, brand had a magnitude of 0.378 and was equally positive, price had a negative magnitude of -0.121, occupational status variable had a positive magnitude of 0.372, while the joint effects of income and occupational status and rice brand and own price were 0.243 and 0.131 respectively. The implication of the results is that any one unit change in income, occupational status of the rice consumers, brand and price in the study area will result in an increase of $0.352,0.372,0.134$ and -0.121 units respectively. The negative sign of the coefficient of price of rice is in consonance with the theoretical expectation. In order words, price naturally has an inverse relationship with consumption expenditure, where any increase in income results in less of the commodity consumed. It is therefore recommended that Governments should provide employment opportunities for the people in order to enhance their income levels, as well as make policies that would encourage local rice production, in order to meet the demand and make rice available to consumers at affordable price in the study area. Also farmers should be encouraged to produce more of the brand of rice available in the area.
\end{abstract}

Key Words: Analysis, Factors, Consumption, Nigeria

\section{Introduction}

Factors affecting rice consumption in Nigeria vary from one locality to another due to different socioeconomic factors. It has therefore become imperative to evaluate the effect of these factors on the socio and economic lives of the population. It was observed that, despite impressive advances in agricultural technology, Nigeria still faces acute shortage in food supply as a result of its low agricultural productivity and yield fluctuations in recent years thereby making the availability of food for human consumption an unpredictable phenomenon [1].

Food is a basic necessity of life therefore, enhancing strategies must not merely be directed at ensuring food security for all, but must also include the need to achieve the consumption of adequate quantities and qualities of safe foods for healthy life of the citizenry [2]. Rice is not an exception because it is the world's most important staple food crop consumed by more than half of the world's population as represented by 2.89 billion people in Asia, 150.3 million people in America and 40 million people in Africa [3]; [4] ; [5] and [6]. It is an important food commodity for most people in the sub-saharan Africa, particularly West Africa, where the consumption of cassava, sorghum and millet has decreased from $61 \%$ in the early 1970 s to $49 \%$ in the early 1990's, while that of rice has increased from 15-20\% over the same period [7]; and [8]. According to annual agricultural survey data, rice is a sustainable food for Nigerians. During the 1960's, Nigeria had average per capita annual rice consumption of $3 \mathrm{~kg}$, which increased to an average of $18 \mathrm{~kg}$ during the 1980's[9]; [10]. Since the mid 1980's, rice consumption has increased at an average annual rate of $11 \%$ with only $3 \%$ explained by population growth. Also, within the decade of the 1990's [11] reported a 14\% annual increase in the demand for rice in Nigeria.

Rice is the world's most important food product as there is hardly any household that survives without eating rice as a full meal for two days, particularly among the middle income earners in Africa. Research has shown that about three billion people world-wide consume rice everyday and that the increasing rate of consumption makes most countries import - dependent on rice [12]. Nigeria still ranks third with Iraq after 
Philipines and China in the group of major rice importing countries in the World [13]. Reasons for the increased rice consumption in these countries include rapid urbanization, ease of preparation that fits easily into urban lifestyle of workers, and its general availability among food vendors and restaurants located in work places, especially in the urban areas.

The rural dwellers whose primary occupation is mostly farming are usually unable to increase production and consequently cannot afford other products they do not produce. This situation often affects their food security situation and deepens their poverty level. The demand for rice in Cross River State of Nigeria is affected by the market prices which have been soaring partly because of increase in population, family occupational structures, in addition to the fact that the local production does not meet the required level of marketable volume, in spite of the long history of rice cultivation and milling by the farmers. Such factors like sex of consumers, level of education, income status, household size, the quality of rice consumed, the availability of rice as well as sources of local rice consumed may be responsible for the increase in the level of rice consumption among others. This research study is therefore initiated to enhance fuller understanding of the effect of some socio-economic factors on rice consumers in the study area.

\section{Materials and Methods}

This study was carried out in Cross River State of Nigeria. Cross River State derived her name from the river Ogono, which passes through the State. The state was created in 1976 by the then General Mohammed Murtala regime. Cross River is a coastal state that is bordered on the north by Benue State, on the west by Ebonyi, and Abia States, on the south by Akwa Ibom State and on the east side by Cameroon. The capital city of the State is Calabar and the major Languages spoken in the State are Ejagham, Efik, Bekwara and Bette. The State is made of 18 Local Government Areas.

Traditionally, the State is one of the most peaceful in the federation, and the State tourism potential remains at the core of the State Government's strategy for development. Two-thirds of the State in covered by the tropical rain forest, making it to be one of the world's biodiversity hot spots. The State is also blessed with mineral resources like oil, and gas, clay, salt, lime stone, kaoline, barite and quartzite. Based on the 2006 National population Census (NPC), it has an estimated population of 2.89 million people, $40 \%$ of which is involved in various economic activities; ranging from subsistence agricultural production to urban commerce and transport business. Presently, agriculture employs about $80 \%$ of the state's labour force, and contributes about $40 \%$ of the gross domestic product (GDP). The state is known to have one of the largest preserved rain forests in the world.

Major crops produced in the state include staple crops like yam, cassava, potato. Other crops include maize, rice, beans, groundnut, sorghum, vegetables, palm produce, rubber, cocoa, kola nut, orange, pears, pineapple and timber products. It has such tourist attractions as Cross River National park, Obudu Cattle Ranch Resort, the rain forests of Afi, the water falls of Agbokim, the Tinapa Business Resort, Calabar Residency Museum and the Calabar Slave Park.

A multi-stage sampling technique was adopted for the research. The sample size for this study was drawn from three (3) Senatorial Districts of the State. From each of the Senatorial Districts, four (4) Local Government Areas were purposively selected to give a total of twelve (12), from which respondents were randomly selected to give a total of two hundred and forty (240). The local governments in the northern senatorial district were obudu (20),Ogoja (20),Yala (25) and Bekwarra (15), to make a total of 80 respondents. In the central, the LGA's were Yakurr (20), Ikom (20), Boki (25) and Obubra to make up 80 respondents, while in the southern senatorial district the LGA's were Biase (20), Udukpani (20), Calabar South (25) and Akpabuyo (15) to make a total of 80 respondents. In order to get the required information and the data for analysis, a well structured questionnaire was designed. Each section of the questionnaire contained sub-sections to enable the researcher get the required information from the respondents. Again, the contents of the questionnaire reflected the study questions/goals, as well as the information needed to find solutions to them.

The designed questionnaires were administered on the respondents. In order to ease communication problems as well guarantee effective data collection, two adhoc enumerators were engaged to serve as gobetween the researcher and the respondents in each of the Local Government Areas; giving a total of twenty four (24). Descriptive statistics was used to analyse the socio-economic characteristics of the respondents. This was done with the use of percentages and frequency. Also, the analysis of covariance (ANCOVA) model used for the estimation of a mixture of qualitative and quantitative exogenous variables was used to determine the functional relationship between consumption expenditure and disposable income $\left(\mathrm{X}_{1 t}\right)$, occupational status $\left(\mathrm{D}_{1 t}\right)$, brand of rice preferred $\left(\mathrm{D}_{2 t}\right)$, and price of rice $\left(\mathrm{X}_{2 \mathrm{t}}\right)$ [14]. The implicit forms of the ANCOVA models are in the form:

$\mathbf{Y}_{t}=\mathbf{f}\left(\mathbf{D}_{1 \mathrm{t}}, \mathbf{X}_{1 \mathrm{t}}\right)$

$\mathbf{Y}_{\mathrm{t} 2}=\mathbf{f}\left(\mathbf{D}_{2 \mathrm{t}}, \mathbf{X}_{2 \mathrm{t}}\right)$

where 
$\mathrm{Y}_{1 \mathrm{t}}=$ Consumption expenditure of rice $(\mathbb{N})$ contingent upon disposable;

$\mathrm{Y}_{2 \mathrm{t}}=$ Consumption expenditure of rice ( $)$ contingent upon price of rice;

$\mathrm{X}_{1 \mathrm{t}}=$ disposable income (N);

$\mathrm{D}_{1 \mathrm{t}}=$ occupational Status (Upper class $=1 ;$ Otherwise $=0$ );

$\mathrm{D}_{2 \mathrm{t}}=$ brand $($ Local $=0$; Otherwise $=1)$; and

$\mathrm{X}_{2 \mathrm{t}}=$ price of rice $(\#)$.

The explicit functional forms of the ANCOVA model is in the form:

$\mathbf{Y}_{\mathbf{t 1}}=\mathbf{a}_{\mathbf{0 1}}+\mathbf{a}_{1} \mathbf{D}_{1 \mathrm{t}}+\mathbf{a}_{1} \mathbf{X}_{1 \mathrm{t}}+\boldsymbol{\beta}_{1}\left(\mathbf{D}_{1 \mathbf{t}} \mathbf{X}_{1 \mathrm{t}}\right)+\mathbf{u}_{\mathrm{t}}$

$Y_{2 t}=a_{02}+a_{2} D_{2 t}+a_{2} X_{2 t}+\beta_{2}\left(D_{2 t} X_{2 t}\right)+u_{t}$

where

$\mathrm{a}_{01}$ and $\mathrm{a}_{\mathrm{0} 2}=$ differential intercepts;

$a_{1}$ and $a_{2}=$ co-efficients of the average effects of income and price of

rice; and

$\beta_{1}$ and $\beta_{2}=$ differential slope coefficients.

To obtain the mean consumption expenditure for occupational status and brand of rice consumed in the study area, the conditional expectation of consumption expenditure was determined thus:

(a) Mean value of consumption for lower class:

$\mathbf{E}\left(\mathbf{Y}_{1 \mathrm{t}} / \mathbf{D}_{1 \mathrm{t}}=\mathbf{0} ; \mathbf{X}_{1 \mathrm{t}}\right)=\mathbf{a}_{0}+\mathbf{a}_{1} \mathbf{X}_{1 \mathrm{t}}$

(b) Mean value of consumption for upper class:

$E\left(Y_{2 t} / \mathbf{D}_{1 \mathrm{t}}=1 ; \mathbf{X}_{1 \mathrm{t}}\right)=\left(\mathbf{a}_{0}+\mathbf{a}_{1}\right)+\left(\mathfrak{a}_{1}+\boldsymbol{\beta}_{1}\right) \mathbf{X}_{1 \mathrm{t}}$

(c) Mean value of consumption for local brands:

$\mathbf{E}\left(\mathbf{Y}_{2 \mathrm{t}} / \mathbf{D}_{\mathbf{t 2}}=\mathbf{0} ; \mathbf{X}_{2 \mathrm{t}}\right)=\mathbf{a}_{0}+\mathbf{a}_{2} \mathbf{X}_{2 \mathrm{t}}$

(d) Mean value of consumption for higher brands:

$E\left(Y_{2 t} / D_{t 2}=1 ; X_{2 t}\right)=\left(a_{0}+a_{2}\right)+\left(\dot{a}_{2}+\beta_{2}\right)$

Equations 5 and 6 can all be obtained when 3 is estimated and 7 and 8 can also be obtained when 4 is estimated..

\section{Results And Discussion}

Results for the socio-economic characteristics of the respondents are presented in Table 1. Out of the two hundred and forty (240) questionnaires administered, only two hundred and twenty one (221) were returned. The table below describes the socio-economic variables analysed in the study.

TABLE1: Socio-economic Variables of the Respondents

\begin{tabular}{lcc}
\hline Variables & Frequency & \% Distribution \\
\hline Age Groups & 41 & 18.5 \\
$20-29$ & 49 & 22.2 \\
$30-39$ & 65 & 29.4 \\
$40-49$ & 66 & 29.9 \\
50 years and above & 221 & 100 \\
Total & & \\
Gender & 124 & 56.1 \\
Male & 97 & 43.9 \\
Female & 221 & 100 \\
Total & & \\
Marital Status & 68 & 30.8 \\
Single & 102 & 46.2 \\
Married & 42 & 19.0 \\
Widow/widower & 9 & 4.0 \\
Divorced & 221 & 100 \\
Total & & \\
Household Size & 34 & 15.4 \\
$1-2$ & 46 & 20.8 \\
3-5 & 81 & 36.7 \\
$5-6$ & 60 & 27.1 \\
11 and above & 221 & 100 \\
Total & & \\
Religion & 167 & 75.6 \\
Christian & & \\
Muslim & 54 & 100 \\
Others & 221 & \\
Total & & 24.0 \\
Level of Education & 53 & 50.7 \\
Never went to school & 112 & 10.8 \\
Primary School & 32 & 100 \\
Secondary School & 24 & \\
Tertiary Institution & 221 & \\
Total & & \\
\hline
\end{tabular}


Source: Field Survey data, 2012

From the above, the results revealed that $18.5 \%$ of the respondents fell within the age bracket of $20-$ $29,22.2 \%$ fell within the age bracket of $30-39,29.4 \%$ fell within the age bracket of $40-49$, while $29.9 \%$ of the respondents were 50 years and above. This indicates that most rice consumers in the study area are between the age of 30 and above. This finding is in consonance with [13], who found that age bracket of 40 years and above show greater appetite for grains and vegetables in the sub-Saharan Africa. They further contended that once they satisfy their basic energy needs, households start to diversify their diets by including animal food sources, dairy products, fruits and vegetables. The results also revealed that out of 221 respondents, 124 were male and 97 were female, representing $56.1 \%$ and $43.9 \%$ respectively. From the above scenario, it shows that rice is consumed by both males and females in the study area. The results also showed that $30.8 \%$ of the respondents were single, $46.2 \%$ were married, $19.0 \%$ were widowed, while $4.0 \%$ were divorced.

On household size, it was revealed that $15.4 \%$ fell within $3-5$ household size, $20.8 \%$ had between $5-$ 6 household size, $36.7 \%$ had between $1-2$ household size and $27.1 \%$ had 11 and above household size. This results suggest that the number of people in a household determines the amount of rice consumed, as it is with any other food item.

On religion, the results showed that $75.6 \%$ were Christians, non was Muslim, while $24.4 \%$ did not belong to any religion. It was also revealed that $24.0 \%$ of the respondents never had any formal education, $50.7 \%$ had primary school education, $14.5 \%$ had secondary school education, while only $10.8 \%$ of the respondents had tertiary education. The findings indicate that most of the respondents in the study area have some form of formal educational background; a situation that could affect the living style of the people. This is in line with the research findings of [13] where more educated households were found to adopt healthier lifestyles, in addition to the fact that other factors like income, age and gender have significant effect on peoples die [15]. However, educational level is seen as the strongest determinant because education is a precondition for the understanding of health and environmental related information needed by both urban and rural people as well as the basis for standard employment which has potential to provide higher income for the population.

TABLE 2: Share of Rice Expenditure and Average Quantity of Rice Consumed

\begin{tabular}{llc}
\hline Average Monthly Income & $=$ & $\$ 32,154$ \\
Average Amount Spent on Rice per day & $=$ & $\$ 1,378$ \\
Average Quantity of Rice Consumed per meal & $=$ & $2.5 \mathrm{~kg}$ \\
\hline
\end{tabular}

Source: Field Survey data, 2012

From Table 2, the average monthly income of an individual in the study area was found to be $\$ 32,154$, the average amount spent on rice consumption per household in a day was $\$ 1,378$, while the average quantity of rice consumed by a household per meal was $2.5 \mathrm{~kg}$.

TABLE 3: Estimates of Conditional Expectation of Consumption Expenditure with Respect to Occupational Status and Disposable Income.

\begin{tabular}{|l|l|l|l|l|}
\hline Independent Variable & Coefficient & Standard Error & F-ratio & t-statistics \\
\hline Constant & 0.776 & 1.320 & 1.465 & 0.588 \\
$\mathrm{D}_{1 \mathrm{t}}$ & 0.372 & 1.020 & & 0.361 \\
$\mathrm{X}_{1 \mathrm{t}}$ & 0.352 & 0.020 & & 17.600 \\
$\mathrm{D}_{1 \mathrm{t}} \mathrm{X}_{1 \mathrm{t}}$ & 0.243 & 1.301 & & 0.109 \\
& & & & \\
\hline
\end{tabular}

$\mathrm{R}^{2}=0.422 ; \mathrm{F}-\mathrm{Ratio}=1.465 ; \mathrm{DW}=1.708 ; \mathrm{AIC}=0.213 ; \mathrm{SC}=0.315$

TABLE 4: Estimates of Conditional Expectation of Consumption Expenditure with Respect to Rice Brand and Price of Rice.

\begin{tabular}{|l|l|l|l|l|}
\hline Independent Variable & Coefficient & Standard Error & F-ratio & t-statistics \\
\hline Constant & 2.439 & 0.217 & 0.636 & 11.233 \\
$\mathrm{D}_{2 \mathrm{t}}$ & 0.134 & 1.081 & & 0.121 \\
$\mathrm{X}_{2 \mathrm{t}}$ & -0.121 & 0.003 & & 43.66 \\
$\mathrm{D}_{2 \mathrm{t}} \mathrm{X}_{2 \mathrm{t}}$ & 0.131 & 0.034 & & 3.853 \\
\hline
\end{tabular}

$\mathrm{R}^{2}=0.221 ; \mathrm{F}-$ Ratio $=0.026 ; \mathrm{DW}=1.559 ; \mathrm{AIC}=2.34 ; \mathrm{SC}=3.173$

The results of the regression analysis undertaken based on the data generated from the field showed the estimates of disposable income $\left(\mathrm{X}_{1 \mathrm{t}}\right)$, occupational status $\left(\mathrm{D}_{1 \mathrm{t}}\right)$, the joint effect of income and occupational status $(\mathrm{X} 1 \mathrm{tD} 1 \mathrm{t})$, rice brand $\left(\mathrm{D}_{2 \mathrm{t}}\right)$, own price $\left(\mathrm{X}_{2 \mathrm{t}}\right)$, and the joint effect of brand and price of rice $\left(\mathrm{D}_{2 \mathrm{t}} \mathrm{X}_{2 \mathrm{t}}\right)$. The coefficients of the defined parameters were $0.352,0.372,0.243,0.134,-0.121$ and 0.131 respectively. In Table 3 , 
the joint effect of income and occupational status was significant at $10 \%$, while the co-efficient of determination $\left(\mathrm{R}^{2}\right)$ was 0.422 or $40 \%$, indicating the proportion of the variation in consumption expenditure accounted for by the model, while the Akaike and Schwarz information criteria, F-ratio ,and Durbin Watson values were 1.708, $0.315,1.422$ and 1.708 respectively. 1 . In Table 4 , the diagnostic statistics viz: $\mathrm{R}^{2}$ Akaike and Schwarz information criteria ,F-ratio and DW had values of 0.22 or $22 \%, 2.34,3.17,0.026$ and 1.559 respectively.

A close comparison of the diagnostic statistics, particularly the Akaike and Schwarz information criteria showed that the estimates of the conditional expectation of consumption expenditure with respect to disposable income and occupational status in Table 3 were more appropriate and valid as the values of Akaike and Schwarz information criteria were lower in Table 3.The minimized values of the Akaike and Schwarz information criteria indicated appropriateness of the specified model. The implication of this results is that any unit increase in income will result in $\$ 0.35$ (35K) increase in consumption. Also, the magnitude of the coefficient of the brand of rice $\left(\mathrm{D}_{2 \mathrm{t}}\right)$ was 0.134 and positive. This also shows that brand among other determinants positively affects the consumption behaviour of the respondents in the study area. For price of rice $\left(\mathrm{X}_{2 \mathrm{t}}\right)$, the magnitude of the coefficient was 0-121. The negative sign shows an inverse relationship between price and consumption and this agrees with the theoretical expectation. In other words, any increase in price of a given commodity will negatively affect the consumption of that commodity. This result is in conformity with the opinion of [16], that price helps the consumer to allocate his or her income to the various goods and services. Also, the coefficient of occupational status $\left(D_{1 t}\right)$ was 0.372 and was positive, showing that the occupational status of the respondents is a significant factor in the determination of rice consumption in the study area.

\section{Conclusion And Recommendations}

Based on the findings of the research, it is concluded that the socio-economic variables such as age, marital status, household size, religion and level of education were considered determinant factors in the consumption of rice in the study area. The results of the sex variable did not show it as a determinant factor. This may be due to the fact that both male and female consume rice in the study area. In the study area, the average monthly income of an individual was $\$ 32.154$, the average amount spent on the consumption of rice per household per day was N1,378, while the average quantity of rice consumed by a household per meal was $2 \mathrm{~kg}$. Based on these findings, it is recommended that governments should provide employment opportunities for the people in the study area as this will enhance their income level. Also, farmers should be encouraged to produce the local brand of rice consumed more in the area, as this will enhance local patronage, thereby improving the income status of the farmers in the area. Also, governments at all levels should make policies that would encourage local production of rice in order to meet the demand of the consumers, as this will mean making rice available to consumers at an affordable price in the study area.

\section{References}

[1] F.S, Idachaba. (1991). The nature of the Nigerian food problem.Journal of Agricultural Science, 7(10), 1991,48-52.

[2] J.K, Olayemi. Food security in Nigeria. Research Report prepared for the Development Policy Centre. ( Ibadan, 1998$): 1-86$.

[3] FAO. African rice economic prospect. Food and Agriculture organization (FAO). (Rome,1996):15-31.

[4] M.Bruntrup. The rice market:Senegal Agric Rural Development Annual Report. Cotonou, 2006,13-23.

[5] IRRI. World rice statistics. International Rice Research Institute.( Manila, 2004):400-439

[6] A. Gulati and S. Narayanan. Rice trade liberalization and poverty. MSSD Discussion paper, No. 51 htt[:deas. Repec( Org/P/Fpr/Mssddp/5/html,2002,69-73.

[7] M.P, Jones. (1995). The rice plant and its environment. West African Rice Development Association (WARDA).( Abijan, 1995,3448.

[8] M.W, Rosegrant, X. Cai and N. Nakagawa. The role of rainfed agriculture in the future of global food production. Environment and production technology division. Discussion paper No. 90, International food policy Research Institute.Washington,2002, $275-283$.

[9] FAO. African development indicator. Food and Agriculture Organization (FAO). ( Rome, 2002): 40-43

[10] G.F. Akpokodje, F. Lancon and O. Erenstein (2001). Nigerians economy:. Final report presented to West Africa Rice Development Association (WARDA). ( Ouake, 2001):55-61

[11] O. Erenstein, F. Lancon ,S.O, Akande, S. Titilela, G. Akpokedje and O.O Ogundele. Rice production in Nigeria: A survey Project Report on the Nigerian rice economy in a competitive world, WARDA. ( Abidjan,2003):23-35

[12] G. Subair. Nigeria spends N100bn yearly to import rice. (Lagos,2008): 32

[13] T.M. Ruel, N. Minot and L. Smith. (2005). Patterns and determinants of grains and vegetables consumption in sub-saharan Africa: A multi-country comparison, Background paper for the join FAO/WGO workshop on fruits and vegetables for health. ( Kobe:2005):54-67.

[14] S. A Salisu. Regression on dummy variables and interpretation of results.Centre for econometric and applied research. Ibadan,2011, 104-145.

[15] A.Ttrichopoulou,,A.,Naska, and T. Costacou. Disparities in food habits across Europe. Proceedings of the Nutrition Society 61(4) 2002:553-558.

[16] C,E. Ferguson and J.P Gould. Macroeconomic theory. (Ontario;Prince-Hall,1075):29-43. 